\title{
Skeletal complications in cancer patients with bone metastases
}

\author{
Shunsuke Tsuzuki ${ }^{1}$, Sun Hee Park ${ }^{1}$, Matthew R. Eber ${ }^{1}$, Christopher M. Peters ${ }^{2}$, and Yusuke \\ Shiozawa ${ }^{1}$ \\ ${ }^{1}$ Department of Cancer Biology and Comprehensive Cancer Center, Wake Forest School of \\ Medicine, Winston-Salem, NC, USA \\ ${ }^{2}$ Department of Anesthesiology, Wake Forest School of Medicine, Winston-Salem, NC, USA
}

\begin{abstract}
Due to significant improvements in current therapies, the life expectancy of cancer patients with bone metastases has dramatically improved. Unfortunately, these patients often experience skeletal complications that significantly impair their quality of life. The major skeletal complications associated with bone metastases include: cancer-induced bone pain, hypercalcemia, pathological bone fractures, metastatic epidural spinal cord compression, and cancer cachexia. Once cancer cells invade the bone, they perturb the normal physiology of the marrow microenvironment, resulting in bone destruction, which is believed to be a direct cause of skeletal complications. However, full understanding of the mechanisms responsible for these complications remains unknown. In this review, we will discuss the complications associated with bone metastases along with matched conventional therapeutic strategies. A better understanding of this topic is crucial, since targeting skeletal complications can improve both morbidity and mortality of patients suffering from bone metastases.
\end{abstract}

\section{Keywords}

Bone metastasis; Skeletal complications; Cancer-induced bone pain; Hypercalcemia; Pathological bone fractures; Metastatic epidural spinal cord compression; Cancer cachexia

\section{Introduction}

Although the survival of prostate cancer patients has improved over the last two decades, when the disease spreads to other organs such as bone, the prognosis worsens drastically. Indeed, the 5-year relative survival rate of localized or regional prostate cancer is nearly $100 \%$; but only $28.2 \%$ of patients with distant metastases survive past 5 years (http:// seer.cancer.gov/statfacts/html/prost.html). In particular, the overall median survival of patients with bone metastases is only 19 months ${ }^{(1)}$. This is due to the fact that distant metastases are difficult to treat or even investigate, because the process of metastasis requires many steps: including detachment from the primary site, circulation throughout the

Corresponding author: Yusuke Shiozawa, MD, PhD, Department of Cancer Biology, Wake Forest School of Medicine, 1 Medical Center Blvd, Winston-Salem, NC 27157-1082, USA, yshiozaw@ wakehealth.edu.

Conflict of interest:

The authors declare that there are no conflicts of interest. 
body, and dissemination to secondary organs ${ }^{(2)}$. Moreover, growing evidence suggests that the interaction between metastatic cancer cells and their microenvironment is a complex but essential component of the metastatic process $(3,4)$.

Once in the marrow, bone metastatic cancer cells take advantage of the normal marrow physiology to survive away from the primary tumor ${ }^{(5)}$. Bone marrow is a unique environment in that it houses both the cells of hematopoietic lineage and the cells that are responsible for bone remodeling (e.g. osteoblasts and osteoclasts). Recent studies have demonstrated that bone metastatic cancer cells home to the osteoblasts, or the hematopoietic stem cell niche ${ }^{(6)}$, which play crucial roles in the early colonization of bone ${ }^{(6,7)}$. These disseminated tumor cells (DTCs) also actively influence bone remodeling (e.g. osteoblastogenesis and osteoclastogenesis) to create a favorable environment for further recruitment and better survival of DTCs within the marrow ${ }^{(8)}$. Subsequently, DTCs become dormant, and eventually regrow. Currently, bone-targeting agents (bisphosphonate (BPs), denosumab) and/or external beam radiotherapy are the standards of care for prevention or delay of skeletal related events (SREs) ${ }^{(9)}$. However, these treatment strategies are not radical, but palliative or supportive. Therefore, there is a strong need to understand the mechanisms of bone metastasis to develop treatments that are more effective.

Generally, patients with advanced stage prostate cancer are treated with androgen deprivation therapy (ADT), whereas patients with early stage, low or intermediate risk prostate cancer can be treated with prostatectomy or radiation. In most cases, ADT is only effective initially, when prostate cancer is first cut off from its preferred growth factor, androgen. However, ADT alone is not sufficient to eliminate prostate cancer. Prostate cancer gradually acquires resistance to androgen deprivation and eventually becomes castration resistant prostate cancer (CRPC), which often presents itself in the form of aggressive bone metastases. Once CRPC spreads to the bone, it is not only incurable, but also causes SREs that devastate one's quality of life (QOL). As if the severe pain associated with bone metastases was not enough, many patients experience spinal cord compression so debilitating they become completely bedridden. It is therefore of the utmost importance to develop therapeutic agents that eradicate bone metastatic diseases, or in the very least improve the QOL of afflicted patients. In order to do this, we need to understand the mechanisms involved in skeletal complications associated with bone metastases.

In this review, we compiled the known molecular mechanisms and current therapeutic strategies, as well as the shortcomings, associated with the four major skeletal complications caused by bone metastases.

\section{Skeletal complications of bone metastasis}

\section{1) Cancer-induced bone pain}

Pain is one of the most frequent complications in cancer patients. In fact, $68 \%$ of all cancer patients with advanced, metastatic or terminal disease experiences pain ${ }^{(10)}$. Specifically, $60-84 \%$ of cancer patients with bone metastasis develop bone pain ${ }^{(11)}$. The pain mediated by bone metastases is often described as "ongoing pain" which is dull and continuous. However, as cancer grows, this pain may become more severe. Bone cancer pain can also 
produce episodes of intense pain often triggered by movement that breakthrough a standard opioid-based regimen (breakthrough pain). Recent studies suggest the following mechanisms of cancer-induced bone pain: (i) Cancer cells directly or indirectly interact with nociceptors in the marrow by secreting chemical mediators such as prostaglandins, nerve growth factor, endothelins, and bradykinin (12); (ii) Cancer cells also interact with surrounding inflammatory cells, such as macrophages and mast cells within the metastatic lesion. These cancer-associated inflammatory cells also secrete chemical mediators which lead to bone pain ${ }^{(12)}$; and (iii) Once cancer cells reach the bone, they interfere with homeostatic bone remodeling. Cancer cells stimulate osteoclastogenesis by secreting factors such as parathyroid hormone-related protein $(\mathbf{P T H r P}){ }^{(13)}$. The resulting osteoclasts can demineralize and destroy regions of bone rich with peripheral nerve innervation, causing bone pain ${ }^{(14)}$. In addition, the bone destruction process leads to an acidic environment, further stimulating pain via $\mathrm{pH}$ sensing channels ${ }^{(15,16)}$. Therefore, blocking the interactions between chemical mediators and their receptors on peripheral nociceptors ${ }^{(12,17)}$, or preventing osteoclastogenesis altogether are both analgesic strategies used for cancerinduced bone pain.

Currently, pain associated with cancer is treated by following the three-step analgesic ladder approach developed by the World Health Organization (WHO) ${ }^{(18,19)}$. The first step of this approach is to use non-opioids such as non-steroidal anti-inflammatory drugs (NSAIDs) or acetaminophen for mild pain. As pain progresses, the patient is next prescribed weak opioids (mild-moderate pain), and finally, a patient with moderate to severe pain is prescribed strong opioids. Although opioids are extremely effective analgesics and as such, are the current mainstay for severe cancer pain management, opioid abuse and addiction are a serious and growing concern ${ }^{(20)}$. Therefore, alternative strategies to reduce opioid use are urgently needed. One such strategy is a combination regimen of non-opioids and opioids, allowing an overall reduction of opioid intake. This combination strategy has been shown to actually improve treatment efficacy in patients with moderate to severe cancer pain (21).

Radiotherapy has also been used for the management of pain caused by bone metastases (22). It has been demonstrated that $60-80 \%$ of patients with bone metastases experience pain relief after radiotherapy (23). Additionally, agents that target bone remodeling, such as BPs and Denosumab, a monoclonal antibody against RANKL, have been reported to relieve pain in patients suffering from bone metastasis ${ }^{(24)}$.

As stated above, NSAIDs are widely used analgesics for cancer-induced bone pain ${ }^{(24)}$, but can have serious side effects including ulcers and bleeding. However, it was recently demonstrated that patients who took a new type of NSAID (a selective cycloxygenase-2 (COX-2) inhibitor) had fewer gastrointestinal side effects than those who took nonselective traditional NSAIDs ${ }^{(25)}$. Although the mechanisms whereby the COX-2 inhibitor relieves pain are still unknown, it has been suggested that COX-2 is responsible for the synthesis of prostaglandins, resulting in inflammation and pain ${ }^{(26)}$. Indeed, selective COX-2 inhibitors attenuated both on-going and movement-evoked bone cancer pain behaviors in mice inoculated with murine osteolytic NCTC 2472 sarcoma cells in the intramedullary space of the femur ${ }^{(27)}$. Additionally, inhibition of COX-2 prevented bone resorption and reduced tumor growth mediated by COX-2 expressing-NCTC 2472 osteosarcoma cells ${ }^{(27)}$. 
Nerve growth factor (NGF), known to promote prenatal nerve growth ${ }^{(28,29)}$, is involved in the adult regulation of both nociceptive and neuropathic pain through one of its receptors, tropomyosin receptor kinase A (Trk A) ${ }^{(30,31)}$. Along with this notion, NGF causes hyperalgesia in adult rats ${ }^{(29)}$, and muscle pain and skin hyperalgesia in humans ${ }^{(32,33)}$. Accumulating evidence suggest a role for NGF in cancer-induced bone pain. In in vivo bone metastatic models of prostate cancer (ACE-1 cells) and breast cancer (MDA-MB-231-BO cells), treatments with antibodies against NGF significantly attenuated cancer-induced bone pain ${ }^{(34,35)}$. More interestingly, growth and metastasis of MDA-MB-231 breast cancer cells in vivo were inhibited by either an NGF blocking antibody or small interfering RNAs specific to NGF, demonstrating in two ways that NGF is involved in both bone metastatic progression and cancer-induced bone pain ${ }^{(36)}$. In several chronic musculoskeletal pain conditions, Tanezumab, a humanized monoclonal antibody against NGF with high selectivity and specificity, demonstrated significant pain relief ${ }^{(37-40)}$. However, Tanezumab failed to improve the analgesic efficacy in cancer patients with bone metastases ${ }^{(41)}$. Since NGF is an attractive and promising target for the treatment of cancer-induced bone pain, further studies in this area are clearly warranted.

Likewise, endothelin-1 (ET-1) is thought to be involved in both pain and tumor outgrowth within the marrow. ET-1 has two distinct receptors: endothelin A receptor (ETAR) and endothelin B receptor (ETBR). ET-1 appears to promote both tumor progression ${ }^{42,43)}$ and pain behavior $(44,45)$ through ETAR. Ongoing and movement-evoked cancer bone pain mediated by ET- 1 expressing 2472 osteosarcoma cells were attenuated by the ETAR selective antagonist ABT-627, but not by the ETBR selective antagonist, A-192621 ${ }^{(44)}$. In addition, local injection of ET-1 enhanced spontaneous pain behaviors of mice with bone cancer, and this tumor-induced nociception was blocked by the ETAR antagonist BQ-123 ${ }^{(46)}$, suggesting that local levels of ET-1 are involved in the development of cancerinduced bone pain. A human breast cancer cell line ZR-75-1 is well known to develop osteoblastic bone lesions in vivo. It has been demonstrated that ZR-75-1 cells express high levels of ET-1, and ETAR antagonist treatments in mice inoculated with ZR-75-1 cells, when compared to vehicle treatments, cause a significant reduction in the number of osteoblastic lesions and overall tumor burden in the marrow ${ }^{(47)}$. In contrast, this strategy did not attenuate the bone metastatic progression of animals inoculated with osteolytic breast and prostate cancer cells ${ }^{(47)}$. These findings suggest that the ET-1/ETAR interaction plays a crucial role in the progression of osteoblastic bone metastases. However, although in a recent-analysis of 9 clincal studies examining ETAR antagonists in patients with CRPC, Atrasentan treated patients had a reduced incidence of bone pain ${ }^{(48)}$, two different small molecule inhibitors of ETAR, Atrasentan and Zibotentan, both failed to improve the survival of CRPC patients with bone metastases $(49,50)$.

Angiotensin II (Ang II), a peptide involved in the control of blood pressure, is also known to have nociceptive capabilities ${ }^{(51)}$. There are two receptors for Ang II: Angiotensin Type I receptor (AT1R); and Angiotensin Type II receptor (AT2R). It has been demonstrated that Ang II mediates pain through the AT2R expressed on sensory neurons ${ }^{(52,53)}$. In a rat model of neuropathic pain, augmented Ang II levels in the dorsal root ganglion (DRG) contributes to hyperexcitability and abnormal sprouting of DRG sensory neurons ${ }^{(52)}$. Consistent with 
these observations, Ang II increases capsaicin-induced neuronal excitability and neurite outgrowth in both cultured rat and human DRG neurons ${ }^{(53)}$. Most importantly, with regards to cancer, increased levels of Ang II were observed in the lumbar DRGs of rats inoculated with AT3B rat prostate cancer cells (APCCs) directly into the tibia, and these APCCbearing animals expressed hypersensitivity compared to sham-operated animals ${ }^{(54)}$. Intriguingly, treatments of a small molecule inhibitor for AT2R decreased the levels of Ang II in DRGs and reduced hypersensitivity in APCC-bearing animals ${ }^{(54)}$. In addition to its effectiveness in reducing cancer-induced bone pain, the AT2R inhibitor showed analgesic effects in a rat model of chronic neuropathic pain ${ }^{(55)}$, whereas AT1R inhibitor did not ${ }^{(53)}$. The mechanisms behind the analgesic effects of AT2R inhibitor treatments were speculated to involve the reduction of $\mathrm{p} 38$ mitogen-activated protein kinase (MAPK) and p44/p42 MAPK activation in sensory neurons within lumbar DRGs ${ }^{(54,55)}$.

An acidic environment within the bone marrow can also cause cancer-induced bone pain ${ }^{(15)}$. Osteoclasts secrete $\mathrm{HCl}$ by expressing high levels of the vacuolar electrogenic $\mathrm{H}^{+}$ATPase ${ }^{(56)}$. The resulting acidic environment following osteoclastic bone resorption is thought to cause pain behaviors through the transient receptor potential vanilloid type 1 receptor (TRPV1) ${ }^{(15)}$, which is a well-known acid sensing ion channel $(26,57,58)$ and also activated by capsaicin an ingredient in hot peppers. Therefore, TRPV1 can also be a potential therapeutic target for cancer-induced bone pain. Indeed, in the 2472 osteosarcomainoculated bone cancer models, a TRPV1 antagonist or genetic deletion of TRPV1 significantly reduced ongoing and movement-evoked nocifencive behaviors ${ }^{(16)}$.

As we discussed earlier, tissue damage, or bone resorption, mediated by osteoclasts is one of the mechanisms of bone pain ${ }^{(59)}$. Therefore, therapeutic strategies that directly target osteoclastic activities have also been used as analgesics for cancer-induced bone pain. BP is an analog of pyrophosphate and an effective inhibitor of bone resorption mediated by osteoclasts. BP inhibits farnesyl diphosphate synthase, and subsequently decreases the level of geranylgenyl disphosphate, which is required for prenylation of GTP-binding proteins in osteoclasts ${ }^{(60)}$. Therefore, BP inactivates osteoclasts and induces their apoptosis. A randomized, placebo-controlled, phase III trial in men with hormone-refractory prostate cancer revealed that patients who received zoledronic acid (ZA: a third generation nitrogen containing BP) experience fewer SREs, compared to those who receive placebo (33.2\% versus $44.2 \%)^{(61)}$. In addition, placebo treated patients experienced more pain than ZAtreated patients ${ }^{(61)}$. In contrast, a double-blind, placebo-controlled trial with first generation BPs, etidronate and clodronate, failed to demonstrate significant pain relief effects in cancer patients with bone metastases ${ }^{(62-64)}$. This suggests that only the newer generation of BPs should be used as analgesics for cancer-induced bone pain.

Osteoclasts express receptor activator of NF- $\mathrm{KB}$ (RANK) which binds RANK ligand (RANKL) expressed by osteoblasts, resulting in osteoclast differentiation ${ }^{(59)}$. Therefore, blocking the RANK/RANKL axis is a promising strategy for relieving cancer-induced bone pain. Osteoblasts also produce a decoy receptor for RANKL, osteoprotegerin (OPG), which inhibits osteoclast formation and activity by binding to RANKL ${ }^{(59)}$. OPG treatments attenuated both ongoing and movement-evoked pain, and osteoclastogenesis in the femurs of mice inoculated with 2472 osteosarcoma cells ${ }^{(65)}$. A fully human immunoglobulin G2 
monoclonal antibody against RANKL, denosumab, has also been widely used for the prevention of SREs associated with bone metastasis ${ }^{(66)}$. The effects of denosumab on SREs were compared with those of ZA in a randomized, double-blind, phase III study in men with castration-resistant bone metastatic prostate cancer ${ }^{(67)}$. In this study, denosumab delayed the occurrence of SREs (20.7 months) compared with ZA (17.1 months). Likewise, a randomized, double-blind, double-dummy phase III study in breast cancer patients with bone metastases showed that denosumab delays the occurrence of SREs better than ZA ${ }^{(68)}$, and consequently, denosumab reduces the severity of pain when compared to ZA ${ }^{(69)}$.

A liposomal cystein proteinase secreted by osteoclasts, cathepsin K, may also be a potential molecular target for inhibiting osteoclast activities ${ }^{(59)}$. Cathepsin $\mathrm{K}$ degrades the demineralized collagenous matrix. It has been reported that mice with osteoclasts without cathepsin K display an osteopetrotic phenotype associated with impaired osteoclastic activities ${ }^{(70)}$. Cathepsin K inhibitor (CKI) reduced 59\% of osteolytic lesions in the tibiae of mice inoculated with cathepsin K-expressing human BT474 breast cancer cells, similar to the $66 \%$ reduction observed with ZA treatments ${ }^{(71)}$. Interestingly, CKI shrunk tumor burden within the marrow, while ZA did not influence tumor size ${ }^{(71)}$. Additionally, CKI failed to decrease the size of subcutaneously implanted tumors, suggesting that CKI specifically targets the bone marrow microenvironment ${ }^{(71)}$. A randomized, double-blind, phase II trial comparing the CKI odanacatib with ZA was performed in breast cancer patients with bone metastases ${ }^{(72)}$. In this study, a urine detectable bone resorption marker (uNTX/Cr: the ratio of N-telopeptide of type I collagen to creatinine) was measured following treatment with either odanacatib or ZA. After 4 weeks of treatments, odanacatib suppressed uNTX/Cr similar to ZA (77\% versus $73 \%$ ). Moreover, odanacatib showed robust efficacy and a favorable benefit/risk profile in a randomized fracture trial in osteoporosis patients ${ }^{(73)}$. Since CKI also inhibits osteoclastic lesions associated with bone metastases, these findings suggest that CKI can be used as an analgesic for patients who suffer from cancer-induced bone pain. Further studies are clearly needed.

\section{2) Hypercalcemia}

Hypercalcemia is a common paraneoplastic syndrome, and is frequently seen in breast cancer, lung cancer, and multiple myeloma ${ }^{(74)}$. In general, $80 \%$ of cancer-induced hypercalcemia is mediated by PTHrP produced by tumor cells ${ }^{(74)}$. PTHrP derived from tumor cells increases serum calcium levels by enhancing calcium reabsorption in the loop of Henle ascending limb and distal convoluted tubule, and inhibiting phosphate reabsorption in the proximal convoluted tubule ${ }^{(75-77)}$. On the other hand, bone resorption caused by bone metastases is responsible for the remaining $20 \%{ }^{(74)}$. Bone metastatic cancer cells also secrete several factors that stimulate osteoclastogenesis, including PTHrP, IL-6, IL-11, and VEGF ${ }^{(8)}$. These factors are known to enhance osteoclast activity by increasing RANKL and inhibiting OPG secretion from osteoblasts. Interestingly, PTHrP secreted from bone metastatic cancer cells contributes to the release of skeletal calcium and phosphate by activating oseteoclastic bone resorption through the PTH/PTHrP receptor expressed on osteoclasts ${ }^{(78)}$. The most common symptoms of hypercalcemia are nausea, vomiting, anorexia, and abdominal pain. Hypercalcemia can also impair cognition (fatigue to coma) and normal cardiac functions (e.g. short QT syndrome, cardiac arrhythmia) ${ }^{(79)}$. 
Surprisingly, it has been reported that approximately half of all patients die within the first month of developing hypercalcemia ${ }^{(80)}$. Thus, prompt and proper treatments are needed.

The principal goals of treatment are to promote renal calciuresis and inhibit pathologic bone resorption. Hydration is essential to increase the glomerular filtration rate, and inhibit calcium reabsorption in the proximal nephron ${ }^{(81)}$. Thereafter, loop diuretics can be used for promoting the renal excretion of calcium ${ }^{(74)}$. Currently, the Food and Drug Administration (FDA) approves the use of BPs ${ }^{(74)}$ and denosumab ${ }^{(82)}$ for the treatment of hypercalcemia of malignancy (HCM) due to their anti-osteoclastic effects. Denosumab is used for the treatment of patients with BP refractory HCM, based on the results from a single-arm multicenter, international Phase II study ${ }^{(83)}$. In this study, $64 \%$ of patients with BP refractory HCM reached complete response (serum calcium levels corrected for albumin $\leq 10.8 \mathrm{mg} / \mathrm{dL}$ ). Moreover, pooled analysis of two randomized, double-blinded, Phase III trials between denosumab and ZA revealed that denosumab significantly delayed the occurrence of HCM and decreased the recurrence risk of HCM compared to ZA. Therefore, denosumab can be used as a first-line therapy for patients with HCM. Calcitonin can also be used, since it is known to interfere with osteoclast functions, stimulate osteoblast activities, increase renal calcium excretion, and inhibit calcium reabsorption by the intestines ${ }^{(84)}$. However, the use of calcitonin is limited since (i) the duration of efficacy is relatively short; (ii) the reduction of calcium levels is not robust; and (iii) calcitonin itself down-regulates calcitonin receptors on osteoclasts ${ }^{(85)}$.

\section{3) Pathological bone fractures}

It has been reported that 9-29\% of patients who suffer from bone metastases develop pathological fractures ${ }^{86,87)}$. In general, pathological fractures are common in the long bones ${ }^{(88)}$, although the spine is the most common site of skeletal metastases ${ }^{(89)}$. Importantly, the 3-year survival rate of patients with bone metastases and pathological fractures is significantly lower than those without pathological fractures (19\% versus $35 \%)^{(87)}$. Moreover, pathological fractures are painful, resulting in further reduced QOL. Therefore, a deep understanding of the pathological fracture risk in bone metastatic disease is an unmet need for the prevention, detection, and treatment of pathological fracture. The following are currently considered to be the risk factors for pathological fracture in patients with bone metastases: (i) increasing pain; (ii) radiographic osteolytic appearance; (iii) lesion size (>25mm); (iv) axial cortical involvement (>30 mm); and (v) circumferential cortical involvement $(>50 \%)^{(90-94)}$.

Patients with pathological fractures are mainly treated with surgery to stabilize the fractured bones with the goal of pain relief, function and mobility restoration, and general QOL improvement ${ }^{(89)}$. Intriguingly, a population-based study of patients with femoral metastases demonstrated that patients who receive prophylactic stabilizations of bone metastatic disease have better survival outcomes than those who receive surgical interventions postfracture ${ }^{(95)}$. Adjuvant radiotherapy is often given to target residual microscopic disease so that disease and fracture recurrence can be prevented ${ }^{(96)}$. Although the appearance of osteolytic bone lesions is a risk factor for malignant fractures, the implementation of 
adjuvant treatments with osteoclast inhibitors for the prevention of malignant fractures remains controversial ${ }^{(97)}$.

\section{4) Metastatic epidural spinal cord compression}

Metastatic epidural spinal cord compression (MESCC) is another oncologic emergency related to bone metastasis, as it leads to reduced life expectancy and QOL if accurate diagnosis and treatments are not immediate ${ }^{(98)}$. MESCC occurs in $15-20 \%$ of patients with bone metastatic cancer, such as prostate, breast, and lung cancer ${ }^{(99)}$. The overall median survival of MESCC patients is 3-6 months, and the improvement of mobility is thought to be a crucial factor to prolonging survival ${ }^{(99)}$. MESCC causes severe pain, motor weakness, sensory deficits, and gait disturbance, and, in some cases the functions of the bladder, bowels, or sexual organs are disturbed $(98,99)$. The preferential location of compression in the spine depends on the size and blood flow of vertebrae: $15 \%$ of MESCC occurs in the cervical spine; $60 \%$ in the thoracic spine; and $25 \%$ in the lumbosacral spine ${ }^{\left({ }^{(9)}\right.}$. MESCC is thought to occur in two ways ${ }^{(99)}$ : (i) direct compression of the spinal cord mediated by perivertebral tumors; and (ii) indirect compression derived from bone tissues in which DTCs grow. The spinal cord is damaged by these compressions or by vascular compromise caused by growing tumors ${ }^{(99)}$. Once arterial flow to the spinal cord is disturbed, MESCC becomes irreversible ${ }^{(100-102)}$.

In most cases, immediate treatment is essential for patients with MESCC. Corticosteroids are the first-line treatment for MESCC, since they are known to stabilize vascular membranes and reduce edema, reduce inflammation, and delay the onset of neurological manifestations (motor power and skills, reflexes, and sensory or any other neurological symptoms) ${ }^{(103)}$. In addition, the therapeutic effects of radiation on MESCC are promising, although appropriate dose and duration are not yet agreed upon. When MESCC patients were treated with high-dose dexamethasone along with radiation, significantly greater numbers of patients were able to walk at 3 months and 6 months, compared to those who received radiation alone ${ }^{(104)}$. Surgery is another powerful mode of relief for spinal compression. A randomized trial demonstrated that patients with MESCC who received direct decompressive surgery were able to walk and maintain their momentum longer (median 122 days) than those who received radiotherapy (median 13 days) ${ }^{(105)}$. More importantly, the patients in the surgery group obtained longer survival benefits (126 days versus 100 days). Although further studies are clearly warranted, these findings suggest that surgical intervention with adjuvant radiotherapy improves the QOL of patients with MESCC.

\section{Discussion/Conclusion}

In this article, we discussed the major skeletal complications of bone metastatic disease including cancer-induced bone pain, hypercalcemia, pathological fractures, and spinal cord compression, and current therapeutic strategies (Table 1). As mentioned earlier, cancer patients with bone metastases often experience severe skeletal complications that significantly impair their QOL. Additionally, recent studies suggest that bone metastasis is associated with the development of cancer cachexia. Cachexia is the term used to describe 
the fatal culmination of symptoms including extreme weight loss, anorexia, muscle wasting, and fatigue ${ }^{(106)}$. Several factors which are enriched in bone matrix, including TGF- $\beta$, Activin A, Myostatin, and GDF-11, are believed to cause cachexia (107-109). Therefore, osteolytic activities associated with bone metastasis surely play important roles in the development of cachexia ${ }^{(110)}$. These findings further suggest that a better understanding of the mechanisms of skeletal complications caused by bone metastasis will aid in developing new therapeutic targets for both treating bone metastatic disease and improving patient QOL.

Once cancer cells invade the bone marrow, they interfere with the normal physiology of the marrow microenvironment. Although genetic mutations in tumor cells contribute largely to the metastatic process and are therefore used as logical therapeutic targets for bone metastasis, understanding of the unique crosstalk between tumor cells and their microenvironment is perhaps less intuitive, but crucial in any efforts to eradicate bone metastatic disease. Although bone destruction initiated by DTCs is widely believed to be a direct cause of skeletal complications (Figure 1), the mechanisms by which DTCs interact with the surrounding bone marrow microenvironment and ultimately cause skeletal complications remain unanswered questions in cancer biology. More importantly, we still do not confidently know if the skeletal complications of bone metastatic disease even influence overall patient survival. Clearly, a better understanding of bone metastasis is necessary if we truly hope to improve patient survival, and revealing the mechanisms of its complications will be equally vital to the improvement of patient well-being.

\section{Acknowledgments}

This work was directly supported by the National Cancer Institute (CA163124; Y Shiozawa), the Department of Defense (W81XWH-14-1-0403; Y Shiozawa), the Prostate Cancer Foundation (Y Shiozawa), and the National Institutes of Health (GM099863; CM Peters). Y Shiozawa is supported as the Translational Research Academy which is supported by the National Center for Advancing Translational Sciences (NCATS), National Institutes of Health, through Grant Award Number UL1TR001420.

\section{Abbreviation}

$\begin{array}{ll}\text { DTC } & \text { Disseminated tumor cell } \\ \text { BPs } & \text { Bisphosphonates } \\ \text { SRE } & \text { Skeletal related event } \\ \text { ADT } & \text { Androgen deprivation therapy } \\ \text { CRPC } & \text { Castration resistant prostate cancer } \\ \text { QOL } & \text { Quality of life } \\ \text { PTHrP } & \text { Parathyroid hormone-related protein } \\ \text { WHO } & \text { The World Health Organization } \\ \text { NSAIDs } & \text { Non-steroidal anti-inflammatory drugs }\end{array}$




\begin{tabular}{|c|c|}
\hline COX-2 & Cycloxygenase-2 \\
\hline NGF & Nerve growth factor \\
\hline Trk A & Tropomyosin receptor kinase A \\
\hline ET-1 & Endothelin-1 \\
\hline ETAR & Endothelin A receptor \\
\hline ETBR & Endothelin B receptor \\
\hline Ang II & Angiotensin II \\
\hline AT1R & Angiotensin type I receptor \\
\hline AT2R & Angiotensin type II receptor \\
\hline DRG & Dorsal root ganglion \\
\hline APCCs & AT3B rat prostate cancer cells \\
\hline MAPK & Mitogen-activated protein kinase \\
\hline TRPV1 & Transient receptor potential vanilloid type 1 receptor \\
\hline $\mathbf{Z A}$ & Zoredronic acid \\
\hline RANK & Receptor activator of NF- $\kappa \mathrm{B}$ \\
\hline RANKL & Receptor activator of NF- $\kappa \mathrm{B}$ ligand \\
\hline OPG & Osteoproteogerin \\
\hline CKI & Cathepsin K inhibitor \\
\hline uNTX/Cr & The ratio of N-telopeptide of type I collagen to creatinine \\
\hline FDA & The Food and Drug Administration \\
\hline HCM & Hypercalcemia of malignancy \\
\hline MESCC & Metastatic epidural spinal cord compression \\
\hline
\end{tabular}

\section{Reference List}

1. Pond GR, Sonpavde G, de Wit R, Eisenberger MA, Tannock IF, Armstrong AJ. The prognostic importance of metastatic site in men with metastatic castration-resistant prostate cancer. Eur Urol. 2014; 65:3-6. [PubMed: 24120464]

2. Christofori G. New signals from the invasive front. Nature. 2006; 441:444-50. [PubMed: 16724056]

3. Sleeman JP. The metastatic niche and stromal progression. Cancer Metastasis Rev. 2012; 31:429-40. [PubMed: 22699312]

4. Murgai M, Giles A, Kaplan R. Physiological, Tumor, and Metastatic Niches: Opportunities and Challenges for Targeting the Tumor Microenvironment. Crit Rev Oncog. 2015; 20:301-14. [PubMed: 26349421] 
5. Olechnowicz SW, Edwards CM. Contributions of the host microenvironment to cancer-induced bone disease. Cancer Res. 2014; 74:1625-31. [PubMed: 24599133]

6. Shiozawa Y, Pedersen EA, Havens AM, et al. Human prostate cancer metastases target the hematopoietic stem cell niche to establish footholds in mouse bone marrow. J Clin Invest. 2011; 121:1298-312. [PubMed: 21436587]

7. Wang H, Yu C, Gao X, et al. The osteogenic niche promotes early-stage bone colonization of disseminated breast cancer cells. Cancer Cell. 2015; 27:193-210. [PubMed: 25600338]

8. Clines GA, Guise TA. Hypercalcaemia of malignancy and basic research on mechanisms responsible for osteolytic and osteoblastic metastasis to bone. Endocr Relat Cancer. 2005; 12:54983. [PubMed: 16172192]

9. Coleman R, Body JJ, Aapro M, Hadji P, Herrstedt J. Bone health in cancer patients: ESMO Clinical Practice Guidelines. Ann Oncol. 2014; 25(Suppl 3):iii124-37. [PubMed: 24782453]

10. van den Beuken-van Everdingen MH, de Rijke JM, Kessels AG, Schouten HC, van Kleef M, Patijn J. Prevalence of pain in patients with cancer: a systematic review of the past 40 years. Ann Oncol. 2007; 18:1437-49. [PubMed: 17355955]

11. Coleman RE. Skeletal complications of malignancy. Cancer. 1997; 80:1588-94. [PubMed: 9362426]

12. Jimenez-Andrade JM, Mantyh WG, Bloom AP, Ferng AS, Geffre CP, Mantyh PW. Bone cancer pain. Ann N Y Acad Sci. 2010; 1198:173-81. [PubMed: 20536932]

13. Liao J, McCauley LK. Skeletal metastasis: Established and emerging roles of parathyroid hormone related protein (PTHrP). Cancer Metastasis Rev. 2006; 25:559-71. [PubMed: 17165129]

14. Peters CM, Ghilardi JR, Keyser CP, et al. Tumor-induced injury of primary afferent sensory nerve fibers in bone cancer pain. Exp Neurol. 2005; 193:85-100. [PubMed: 15817267]

15. Yoneda T, Hiasa M, Nagata Y, Okui T, White F. Contribution of acidic extracellular microenvironment of cancer-colonized bone to bone pain. Biochim Biophys Acta. 2015; 1848:2677-84. [PubMed: 25687976]

16. Ghilardi JR, Rohrich H, Lindsay TH, et al. Selective blockade of the capsaicin receptor TRPV1 attenuates bone cancer pain. J Neurosci. 2005; 25:3126-31. [PubMed: 15788769]

17. Mantyh PW. Bone cancer pain: from mechanism to therapy. Curr Opin Support Palliat Care. 2014; 8:83-90. [PubMed: 24792411]

18. McGrath PA. Development of the World Health Organization Guidelines on Cancer Pain Relief and Palliative Care in Children. J Pain Symptom Manage. 1996; 12:87-92. [PubMed: 8754986]

19. Burton AW, Cleeland CS. Cancer pain: progress since the WHO guidelines. Pain Pract. 2001; 1:236-42. [PubMed: 17134407]

20. Pergolizzi JV, Zampogna G, Taylor R, Gonima E, Posada J, Raffa RB. A Guide for Pain Management in Low and Middle Income Communities. Managing the Risk of Opioid Abuse in Patients with Cancer Pain. Front Pharmacol. 2016; 7:42. [PubMed: 26973529]

21. Nabal M, Librada S, Redondo MJ, Pigni A, Brunelli C, Caraceni A. The role of paracetamol and nonsteroidal anti-inflammatory drugs in addition to WHO Step III opioids in the control of pain in advanced cancer. A systematic review of the literature. Palliat Med. 2012; 26:305-12. [PubMed: 22126843]

22. Chow E, Harris K, Fan G, Tsao M, Sze WM. Palliative radiotherapy trials for bone metastases: a systematic review. J Clin Oncol. 2007; 25:1423-36. [PubMed: 17416863]

23. Lutz S, Berk L, Chang E, et al. Palliative radiotherapy for bone metastases: an ASTRO evidencebased guideline. Int J Radiat Oncol Biol Phys. 2011; 79:965-76. [PubMed: 21277118]

24. Ripamonti CI, Santini D, Maranzano E, Berti M, Roila F. Management of cancer pain: ESMO Clinical Practice Guidelines. Ann Oncol. 2012; 23(Suppl 7):vii139-54. [PubMed: 22997447]

25. van der Linden MW, Gaugris S, Kuipers EJ, et al. COX-2 inhibitors: complex association with lower risk of hospitalization for gastrointestinal events compared to traditional NSAIDs plus proton pump inhibitors. Pharmacoepidemiol Drug Saf. 2009; 18:880-90. [PubMed: 19593747]

26. Julius D, Basbaum AI. Molecular mechanisms of nociception. Nature. 2001; 413:203-10. [PubMed: 11557989] 
27. Sabino MA, Ghilardi JR, Jongen JL, et al. Simultaneous reduction in cancer pain, bone destruction, and tumor growth by selective inhibition of cyclooxygenase-2. Cancer Res. 2002; 62:7343-9. [PubMed: 12499278]

28. Hirose M, Kuroda Y, Murata E. NGF/TrkA Signaling as a Therapeutic Target for Pain. Pain Pract. 2016; 16:175-82. [PubMed: 26452158]

29. Lewin GR, Ritter AM, Mendell LM. Nerve growth factor-induced hyperalgesia in the neonatal and adult rat. J Neurosci. 1993; 13:2136-48. [PubMed: 8478693]

30. Thacker MA, Clark AK, Marchand F, McMahon SB. Pathophysiology of peripheral neuropathic pain: immune cells and molecules. Anesth Analg. 2007; 105:838-47. [PubMed: 17717248]

31. Basbaum AI, Bautista DM, Scherrer G, Julius D. Cellular and molecular mechanisms of pain. Cell. 2009; 139:267-84. [PubMed: 19837031]

32. Petty BG, Cornblath DR, Adornato BT, et al. The effect of systemically administered recombinant human nerve growth factor in healthy human subjects. Ann Neurol. 1994; 36:244-6. [PubMed: 8053664]

33. Dyck PJ, Peroutka S, Rask C, et al. Intradermal recombinant human nerve growth factor induces pressure allodynia and lowered heat-pain threshold in humans. Neurology. 1997; 48:501-5. [PubMed: 9040746]

34. Halvorson KG, Kubota K, Sevcik MA, et al. A blocking antibody to nerve growth factor attenuates skeletal pain induced by prostate tumor cells growing in bone. Cancer Res. 2005; 65:9426-35. [PubMed: 16230406]

35. Bloom AP, Jimenez-Andrade JM, Taylor RN, et al. Breast cancer-induced bone remodeling, skeletal pain, and sprouting of sensory nerve fibers. J Pain. 2011; 12:698-711. [PubMed: 21497141]

36. Adriaenssens E, Vanhecke E, Saule P, et al. Nerve growth factor is a potential therapeutic target in breast cancer. Cancer Res. 2008; 68:346-51. [PubMed: 18199526]

37. Lane NE, Schnitzer TJ, Birbara CA, et al. Tanezumab for the treatment of pain from osteoarthritis of the knee. N Engl J Med. 2010; 363:1521-31. [PubMed: 20942668]

38. Brown MT, Murphy FT, Radin DM, Davignon I, Smith MD, West CR. Tanezumab reduces osteoarthritic knee pain: results of a randomized, double-blind, placebo-controlled phase III trial. J Pain. 2012; 13:790-8. [PubMed: 22784777]

39. Brown MT, Murphy FT, Radin DM, Davignon I, Smith MD, West CR. Tanezumab reduces osteoarthritic hip pain: results of a randomized, double-blind, placebo-controlled phase III trial. Arthritis Rheum. 2013; 65:1795-803. [PubMed: 23553790]

40. Katz N, Borenstein DG, Birbara C, et al. Efficacy and safety of tanezumab in the treatment of chronic low back pain. Pain. 2011; 152:2248-58. [PubMed: 21696889]

41. Sopata M, Katz N, Carey W, et al. Efficacy and safety of tanezumab in the treatment of pain from bone metastases. Pain. 2015; 156:1703-13. [PubMed: 25919474]

42. Pinto A, Merino M, Zamora P, Redondo A, Castelo B, Espinosa E. Targeting the endothelin axis in prostate carcinoma. Tumour Biol. 2012; 33:421-6. [PubMed: 22203496]

43. Nelson JB, Carducci MA. The role of endothelin-1 and endothelin receptor antagonists in prostate cancer. BJU Int. 2000; 85(Suppl 2):45-8. [PubMed: 10781185]

44. Peters CM, Lindsay TH, Pomonis JD, et al. Endothelin and the tumorigenic component of bone cancer pain. Neuroscience. 2004; 126:1043-52. [PubMed: 15207337]

45. Pomonis JD, Rogers SD, Peters CM, Ghilardi JR, Mantyh PW. Expression and localization of endothelin receptors: implications for the involvement of peripheral glia in nociception. $\mathrm{J}$ Neurosci. 2001; 21:999-1006. [PubMed: 11157085]

46. Wacnik PW, Eikmeier LJ, Ruggles TR, et al. Functional interactions between tumor and peripheral nerve: morphology, algogen identification, and behavioral characterization of a new murine model of cancer pain. J Neurosci. 2001; 21:9355-66. [PubMed: 11717369]

47. Yin JJ, Mohammad KS, Kakonen SM, et al. A causal role for endothelin-1 in the pathogenesis of osteoblastic bone metastases. Proc Natl Acad Sci U S A. 2003; 100:10954-9. [PubMed: 12941866]

48. Qiao L, Liang Y, Li N, et al. Endothelin-A receptor antagonists in prostate cancer treatment-a meta-analysis. Int J Clin Exp Med. 2015; 8:3465-73. [PubMed: 26064237] 
49. Nelson JB, Fizazi K, Miller K, et al. Phase 3, randomized, placebo-controlled study of zibotentan (ZD4054) in patients with castration-resistant prostate cancer metastatic to bone. Cancer. 2012; 118:5709-18. [PubMed: 22786751]

50. Carducci MA, Saad F, Abrahamsson PA, et al. A phase 3 randomized controlled trial of the efficacy and safety of atrasentan in men with metastatic hormone-refractory prostate cancer. Cancer. 2007; 110:1959-66. [PubMed: 17886253]

51. Patil J, Schwab A, Nussberger J, Schaffner T, Saavedra JM, Imboden H. Intraneuronal angiotensinergic system in rat and human dorsal root ganglia. Regul Pept. 2010; 162:90-8. [PubMed: 20346377]

52. Smith MT, Woodruff TM, Wyse BD, Muralidharan A, Walther T. A small molecule angiotensin II type 2 receptor $(\mathrm{AT}(2) \mathrm{R})$ antagonist produces analgesia in a rat model of neuropathic pain by inhibition of p38 mitogen-activated protein kinase (MAPK) and p44/p42 MAPK activation in the dorsal root ganglia. Pain Med. 2013; 14:1557-68. [PubMed: 23742186]

53. Anand U, Facer P, Yiangou Y, et al. Angiotensin II type 2 receptor (AT2 R) localization and antagonist-mediated inhibition of capsaicin responses and neurite outgrowth in human and rat sensory neurons. Eur J Pain. 2013; 17:1012-26. [PubMed: 23255326]

54. Muralidharan A, Wyse BD, Smith MT. Analgesic efficacy and mode of action of a selective small molecule angiotensin II type 2 receptor antagonist in a rat model of prostate cancer-induced bone pain. Pain Med. 2014; 15:93-110. [PubMed: 24433468]

55. Smith MT, Wyse BD, Edwards SR. Small molecule angiotensin II type 2 receptor (AT(2)R) antagonists as novel analgesics for neuropathic pain: comparative pharmacokinetics, radioligand binding, and efficacy in rats. Pain Med. 2013; 14:692-705. [PubMed: 23489258]

56. Blair HC. How the osteoclast degrades bone. Bioessays. 1998; 20:837-46. [PubMed: 9819571]

57. Reeh PW, Kress M. Molecular physiology of proton transduction in nociceptors. Curr Opin Pharmacol. 2001; 1:45-51. [PubMed: 11712534]

58. Nagae M, Hiraga T, Yoneda T. Acidic microenvironment created by osteoclasts causes bone pain associated with tumor colonization. J Bone Miner Metab. 2007; 25:99-104. [PubMed: 17323179]

59. Rodan GA, Martin TJ. Therapeutic approaches to bone diseases. Science. 2000; 289:1508-14. [PubMed: 10968781]

60. Coxon FP, Helfrich MH, Van't Hof R, et al. Protein geranylgeranylation is required for osteoclast formation, function, and survival: inhibition by bisphosphonates and GGTI-298. J Bone Miner Res. 2000; 15:1467-76. [PubMed: 10934645]

61. Saad F, Gleason DM, Murray R, et al. A randomized, placebo-controlled trial of zoledronic acid in patients with hormone-refractory metastatic prostate carcinoma. J Natl Cancer Inst. 2002; 94:1458-68. [PubMed: 12359855]

62. Smith JA Jr. Palliation of painful bone metastases from prostate cancer using sodium etidronate: results of a randomized, prospective, double-blind, placebo-controlled study. J Urol. 1989; 141:85-7. [PubMed: 2462069]

63. Strang P, Nilsson S, Brandstedt S, et al. The analgesic efficacy of clodronate compared with placebo in patients with painful bone metastases from prostatic cancer. Anticancer Res. 1997; 17:4717-21. [PubMed: 9494595]

64. Kylmala T, Taube T, Tammela TL, Risteli L, Risteli J, Elomaa I. Concomitant i.v. and oral clodronate in the relief of bone pain--a double-blind placebo-controlled study in patients with prostate cancer. Br J Cancer. 1997; 76:939-42. [PubMed: 9328156]

65. Luger NM, Honore P, Sabino MA, et al. Osteoprotegerin diminishes advanced bone cancer pain. Cancer Res. 2001; 61:4038-47. [PubMed: 11358823]

66. Dougall WC. Molecular pathways: osteoclast-dependent and osteoclast-independent roles of the RANKL/RANK/OPG pathway in tumorigenesis and metastasis. Clin Cancer Res. 2012; 18:32635. [PubMed: 22031096]

67. Fizazi K, Carducci M, Smith M, et al. Denosumab versus zoledronic acid for treatment of bone metastases in men with castration-resistant prostate cancer: a randomised, double-blind study. Lancet. 2011; 377:813-22. [PubMed: 21353695] 
68. Stopeck AT, Lipton A, Body JJ, et al. Denosumab compared with zoledronic acid for the treatment of bone metastases in patients with advanced breast cancer: a randomized, double-blind study. $\mathrm{J}$ Clin Oncol. 2010; 28:5132-9. [PubMed: 21060033]

69. Cleeland CS, Body JJ, Stopeck A, et al. Pain outcomes in patients with advanced breast cancer and bone metastases: results from a randomized, double-blind study of denosumab and zoledronic acid. Cancer. 2013; 119:832-8. [PubMed: 22951813]

70. Saftig P, Hunziker E, Wehmeyer O, et al. Impaired osteoclastic bone resorption leads to osteopetrosis in cathepsin-K-deficient mice. Proc Natl Acad Sci U S A. 1998; 95:13453-8. [PubMed: 9811821]

71. Le Gall C, Bellahcene A, Bonnelye E, et al. A cathepsin K inhibitor reduces breast cancer induced osteolysis and skeletal tumor burden. Cancer Res. 2007; 67:9894-902. [PubMed: 17942921]

72. Jensen AB, Wynne C, Ramirez G, et al. The cathepsin K inhibitor odanacatib suppresses bone resorption in women with breast cancer and established bone metastases: results of a 4-week, double-blind, randomized, controlled trial. Clin Breast Cancer. 2010; 10:452-8. [PubMed: 21147688]

73. Bone HG, Dempster DW, Eisman JA, et al. Odanacatib for the treatment of postmenopausal osteoporosis: development history and design and participant characteristics of LOFT, the LongTerm Odanacatib Fracture Trial. Osteoporos Int. 2015; 26:699-712. [PubMed: 25432773]

74. Stewart AF. Clinical practice. Hypercalcemia associated with cancer. N Engl J Med. 2005; 352:373-9. [PubMed: 15673803]

75. Gesek FA, Friedman PA. On the mechanism of parathyroid hormone stimulation of calcium uptake by mouse distal convoluted tubule cells. J Clin Invest. 1992; 90:749-58. [PubMed: 1522230]

76. Pfister MF, Lederer E, Forgo J, et al. Parathyroid hormone-dependent degradation of type II Na+/Pi cotransporters. J Biol Chem. 1997; 272:20125-30. [PubMed: 9242686]

77. Horiuchi N, Caulfield MP, Fisher JE, et al. Similarity of synthetic peptide from human tumor to parathyroid hormone in vivo and in vitro. Science. 1987; 238:1566-8. [PubMed: 3685994]

78. Abou-Samra AB, Juppner H, Force T, et al. Expression cloning of a common receptor for parathyroid hormone and parathyroid hormone-related peptide from rat osteoblast-like cells: a single receptor stimulates intracellular accumulation of both cAMP and inositol trisphosphates and increases intracellular free calcium. Proc Natl Acad Sci U S A. 1992; 89:2732-6. [PubMed: 1313566]

79. Clines GA. Mechanisms and treatment of hypercalcemia of malignancy. Curr Opin Endocrinol Diabetes Obes. 2011; 18:339-46. [PubMed: 21897221]

80. Ralston SH, Gallacher SJ, Patel U, Campbell J, Boyle IT. Cancer-associated hypercalcemia: morbidity and mortality. Clinical experience in 126 treated patients. Ann Intern Med. 1990; 112:499-504. [PubMed: 2138442]

81. Hosking DJ, Cowley A, Bucknall CA. Rehydration in the treatment of severe hypercalcaemia. Q J Med. 1981; 50:473-81. [PubMed: 7342172]

82. Thosani S, Hu MI. Denosumab: a new agent in the management of hypercalcemia of malignancy. Future Oncol. 2015; 11:2865-71. [PubMed: 26403973]

83. Hu MI, Glezerman IG, Leboulleux S, et al. Denosumab for treatment of hypercalcemia of malignancy. J Clin Endocrinol Metab. 2014; 99:3144-52. [PubMed: 24915117]

84. Sternlicht H, Glezerman IG. Hypercalcemia of malignancy and new treatment options. Ther Clin Risk Manag. 2015; 11:1779-88. [PubMed: 26675713]

85. Purdue BW, Tilakaratne N, Sexton PM. Molecular pharmacology of the calcitonin receptor. Receptors Channels. 2002; 8:243-55. [PubMed: 12529940]

86. Aaron AD. Treatment of metastatic adenocarcinoma of the pelvis and the extremities. J Bone Joint Surg Am. 1997; 79:917-32. [PubMed: 9199392]

87. Bohm P, Huber J. The surgical treatment of bony metastases of the spine and limbs. J Bone Joint Surg Br. 2002; 84:521-9. [PubMed: 12043772]

88. Sarahrudi K, Hora K, Heinz T, Millington S, Vecsei V. Treatment results of pathological fractures of the long bones: a retrospective analysis of 88 patients. Int Orthop. 2006; 30:519-24. [PubMed: 16944144] 
89. Bryson DJ, Wicks L, Ashford RU. The investigation and management of suspected malignant pathological fractures: a review for the general orthopaedic surgeon. Injury. 2015; 46:1891-9. [PubMed: 26254572]

90. Parrish FF, Murray JA. Surgical treatment for secondary neoplastic fractures. A retrospective study of ninety-six patients. J Bone Joint Surg Am. 1970; 52:665-86. [PubMed: 4097976]

91. Snell W, Beals RK. Femoral Metastases and Fractures from Breast Cancer. Surg Gynecol Obstet. 1964; 119:22-4. [PubMed: 14179346]

92. Yazawa Y, Frassica FJ, Chao EY, Pritchard DJ, Sim FH, Shives TC. Metastatic bone disease. A study of the surgical treatment of 166 pathologic humeral and femoral fractures. Clin Orthop Relat Res. 1990:213-9.

93. Menck H, Schulze S, Larsen E. Metastasis size in pathologic femoral fractures. Acta Orthop Scand. 1988; 59:151-4. [PubMed: 3364183]

94. Van der Linden YM, Dijkstra PD, Kroon HM, et al. Comparative analysis of risk factors for pathological fracture with femoral metastases. J Bone Joint Surg Br. 2004; 86:566-73. [PubMed: 15174555]

95. Ristevski B, Jenkinson RJ, Stephen DJ, et al. Mortality and complications following stabilization of femoral metastatic lesions: a population-based study of regional variation and outcome. Can $\mathrm{J}$ Surg. 2009; 52:302-8. [PubMed: 19680515]

96. Frassica DA. General principles of external beam radiation therapy for skeletal metastases. Clin Orthop Relat Res. 2003:S158-64. [PubMed: 14600606]

97. Wolanczyk MJ, Fakhrian K, Adamietz IA. Radiotherapy, Bisphosphonates and Surgical Stabilization of Complete or Impending Pathologic Fractures in Patients with Metastatic Bone Disease. J Cancer. 2016; 7:121-4. [PubMed: 26722368]

98. Prasad D, Schiff D. Malignant spinal-cord compression. Lancet Oncol. 2005; 6:15-24. [PubMed: 15629272]

99. Cole JS, Patchell RA. Metastatic epidural spinal cord compression. Lancet Neurol. 2008; 7:45966. [PubMed: 18420159]

100. Ushio Y, Posner R, Posner JB, Shapiro WR. Experimental spinal cord compression by epidural neoplasm. Neurology. 1977; 27:422-9. [PubMed: 558545]

101. Ramsey R, Doppman JL. The effects of epidural masses on spinal cord blood flow. An experimental study in monkeys. Radiology. 1973; 107:99-103. [PubMed: 4632002]

102. Kato A, Ushio Y, Hayakawa T, Yamada K, Ikeda H, Mogami H. Circulatory disturbance of the spinal cord with epidural neoplasm in rats. J Neurosurg. 1985; 63:260-5. [PubMed: 3926963]

103. Fawzy M, El-Beltagy M, Shafei ME, et al. Intraspinal neuroblastoma: Treatment options and neurological outcome of spinal cord compression. Oncol Lett. 2015; 9:907-11. [PubMed: 25624912]

104. Sorensen S, Helweg-Larsen S, Mouridsen H, Hansen HH. Effect of high-dose dexamethasone in carcinomatous metastatic spinal cord compression treated with radiotherapy: a randomised trial. Eur J Cancer. 1994; 30A:22-7. [PubMed: 8142159]

105. Patchell RA, Tibbs PA, Regine WF, et al. Direct decompressive surgical resection in the treatment of spinal cord compression caused by metastatic cancer: a randomised trial. Lancet. 2005; 366:643-8. [PubMed: 16112300]

106. Andreyev HJ, Norman AR, Oates J, Cunningham D. Why do patients with weight loss have a worse outcome when undergoing chemotherapy for gastrointestinal malignancies? Eur J Cancer. 1998; 34:503-9. [PubMed: 9713300]

107. Sakai R, Eto Y. Involvement of activin in the regulation of bone metabolism. Mol Cell Endocrinol. 2001; 180:183-8. [PubMed: 11451590]

108. Wildemann B, Kadow-Romacker A, Haas NP, Schmidmaier G. Quantification of various growth factors in different demineralized bone matrix preparations. J Biomed Mater Res A. 2007; 81:437-42. [PubMed: 17117475]

109. Lee SJ, Reed LA, Davies MV, et al. Regulation of muscle growth by multiple ligands signaling through activin type II receptors. Proc Natl Acad Sci U S A. 2005; 102:18117-22. [PubMed: 16330774] 
110. Waning DL, Mohammad KS, Reiken S, et al. Excess TGF-beta mediates muscle weakness associated with bone metastases in mice. Nat Med. 2015; 21:1262-71. [PubMed: 26457758] 


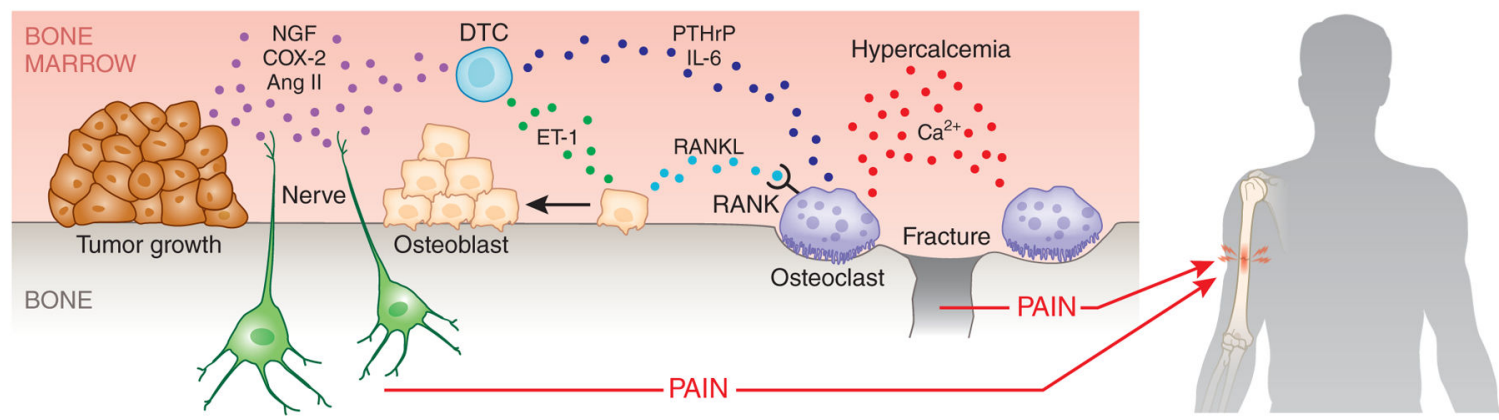

Figure 1. The mechanisms whereby disseminated tumor cells are directly involved in the development of skeletal complications associated with bone metastasis Growing evidence suggests that once in the marrow, DTCs create a favorable microenvironment for their own metastatic progression by interfering with the normal functions of bone marrow. Indeed, DTCs disturb bone remodeling by altering the balance between osteoclastogenesis and osteoblastogenesis. Osteolytic tumor cells stimulate osteoclastic activities by expressing PTHrP or IL-6, and/or by inducing RANKL secretion by osteoblasts. Osteoclastogenesis mediated by DTCs plays a crucial role in the development of serious complications involved with bone metastasis, including bone pain, hypercalcemia, and malignant fracture. In addition, ET-1 expressed by DTCs develops osteoblastic metastatic lesions in the bone and is related to cancer-induced bone pain. At the same time, DTCs engage with sensory neurons in the marrow directly through NGF, COX-2, and Ang II signaling pathways, resulting in cancer-induced bone pain. These pain transmitters may also affect metastatic growth. Therefore, targeting bone remodeling and blocking the cancer/nerve interactions may be a successful therapeutic strategy for eradicating bone metastatic disease and improving patient quality of life.

DTC: disseminated tumor cell; OB: osteoblast; OC: osteoclast; PTHrP: parathyroid hormone-related protein; IL-6: interleukin-6; RANK: receptor activator of nuclear factor $\kappa \mathrm{B}$ ligand; RANKL: receptor activator of nuclear factor $\kappa \mathrm{B}$ ligand; ET-1: endothelin-1; NGF: nerve growth factor; COX-2: cycloxygenase-2; Ang II: angiotensin II. 


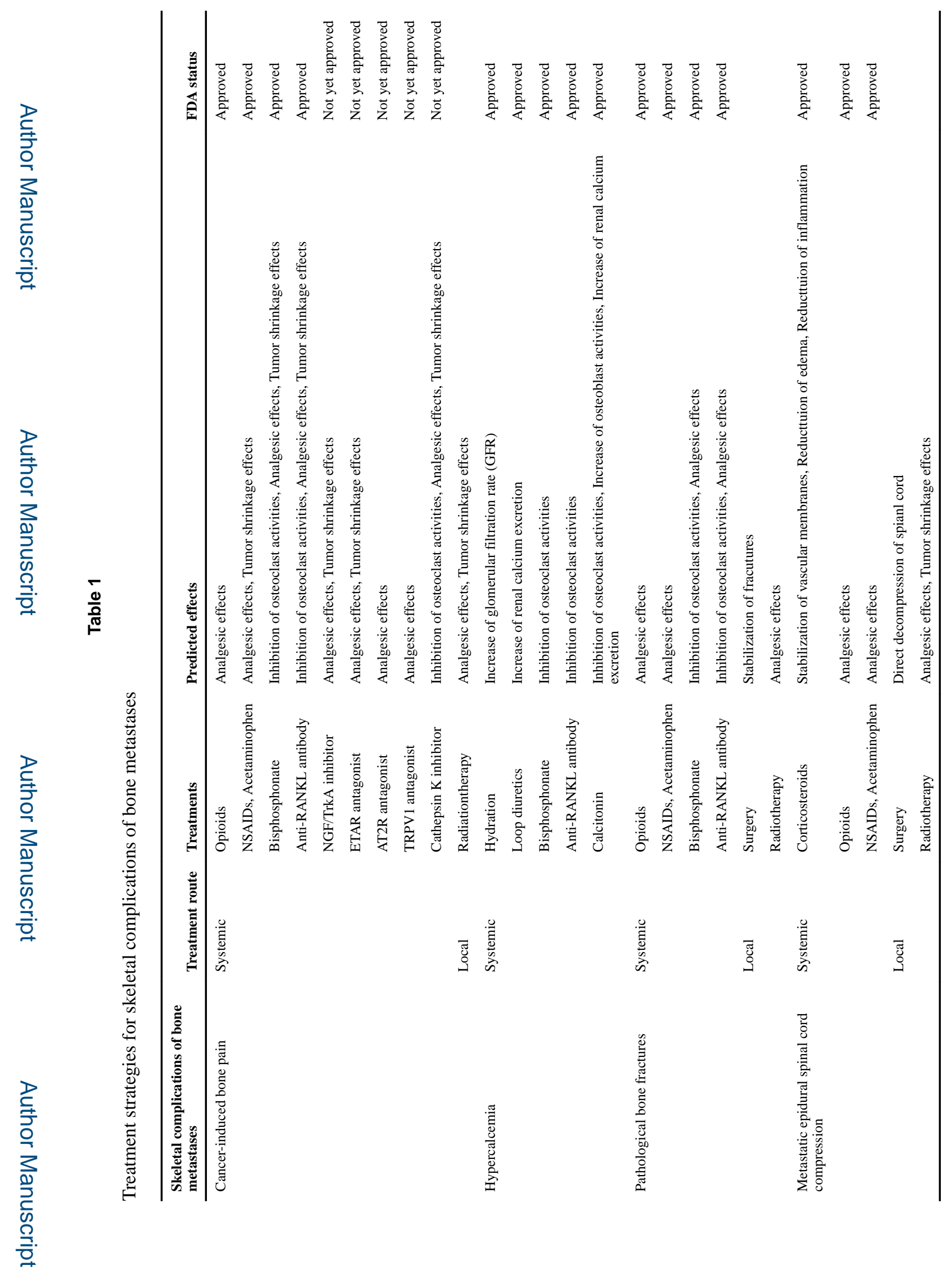

Int J Urol. Author manuscript; available in PMC 2017 December 06. 